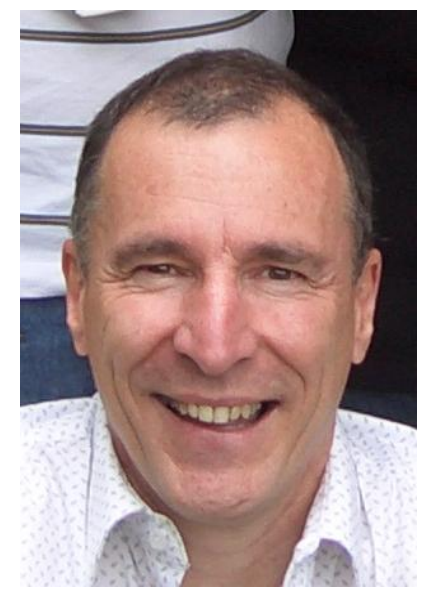

\title{
REPLICATION STUDY: UNDERGRADUATE STUDENTS BALANCING PAID SEMESTER WORK AND STUDY
}

\author{
Edgar Burns \\ School of Social Sciences, La Trobe \\ University, Melbourne \\ Noel Yahanpath
}

Faculty of Business and Computing,

Eastern Institute of Technology, Napier

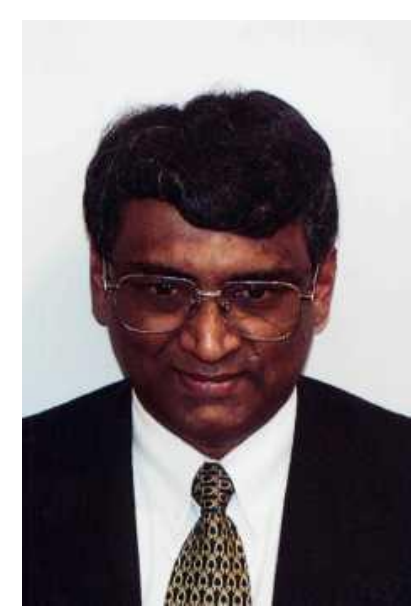

\begin{abstract}
The current study of student semester-time paid work uses the questionnaire from the earlier by Manthei \& Gilmore. They gathered data from an Education Faculty, 83 undergraduates using a questionnaire asking about degree study and part-time paid work while studying. They note in their article that there is no similar data in New Zealand (2005, p. 202). While a number of Australian studies can be found in the literature, the aim of the present study is in replicating Manthei and Gilmore's work to provide additional New Zealand data and also to see whether findings are consistent with the polytechnic sector. Further, two developments, first, the move to cap university places, and second, tighten quality assurance focus on student achievement and retention, will have consequences for all institutions in the tertiary system. Measuring students' part-time paid work is an important aspect in assessing consequences for students' academic work, and policy settings that might follow. Whether the results differ or are similar, this research process widens out the evidential base of the earlier study. Manthei \& Gilmore were at pains in the conclusion of their article to caution about over-generalisation from their one study.
\end{abstract}

\section{Introduction}

This paper presents initial findings from a study of semester-time paid work by tertiary students at one New Zealand polytechnic. In examining the effect of semester paid employment on university students' lives, Manthei and Gilmore (2005, p. 202) state that 'There is no similar data in New Zealand'. This paper presents the first reported results from the replication of that study at a New Zealand Technical Institute. Further results will be described in future reports. The Manthei and Gilmore study at the University of Canterbury surveyed two second-year education courses in 2002. Eighty seven percent of the respondents were women. Paper questionnaires were distributed at the start of one class and collected at the end of the class.

The shifting terrain - why students work In their study Manthei and Gilmore (2005, pp. 202-3) described the changing New Zealand tertiary education environment. They outlined the increase in student numbers in the 1990s. They also outlined the radical changes in educational policy, on the one hand a new system for charging students tuition fees, and at the same time establishing a student loan scheme. Students could borrow the cost of their tuition but had to repay the debt after 
graduating. Enormous sums were borrowed under this scheme. By 2004 the median amount borrowed was about ten thousand dollars and the national student almost seven billion dollars. The inference from this new educational environment and the personal debt students have is that, the majority of students reported working at some stage during the year in order to pay for their education and hold the level of their student loans.

As the phenomenon of students doing paid work during semester time has become more widespread in a number of countries, greater interest in understanding the significance of paid semester work has lead to other research projects. Other research similar to the present project is a topic not explored in this paper. However, such studies include for example: Hunt, Lincoln and Walker (2004), RMIT University (2004), Lingard (2007), Plimmer (2007), and Bernhard (nd). Black (2010) recently commented, 'A track record of part-time work or unpaid internships is fast becoming essential for graduates trying to get a foot on the career ladder.' Even though the present study aims to replicate as closely as possible the earlier research, it appears that at the same time the reasons for student paid work during semester time may be undergoing a shift.

Thus, a first difference in the explanatory frame offered by Manthei and Gilmore is Black's important point about work readiness. This is not a matter of disagreement, but an additional factor about what may motivate paid work participation. A further area of explanation that should be borne in mind in considering findings about student paid work participation, is the range of social influences such as possible desirability or at least acceptability among peers of doing paid work. Yet another influence may lie in the large increase in student involvement in tertiary education in this new fee and borrowing environment. That is, increasing student numbers, while meeting the desirable goal of social inclusion, is by that same process bringing onto campus students who may be less well resourced financially to meet the outgoings of student life.

Identifying these possible additional factors to account for students doing paid work during semester time is not a statement that they are mutually exclusive. On the contrary, with continuing development of education policy and practice, it simply draws attention to the complexity of interpreting the 'whys' and 'hows' of student paid work. It should also assist in avoiding mechanical replication of the previous study Manthei and Gilmore. A key underlying question that frames these studies and other research into semester time paid work is whether, or to what extent, or in what ways, paid semester work has negative consequences for tertiary students whose primary goal and activities are focused on gaining a degree.

Tertiary Education Strategy 2010-2015 why students work

The New Zealand Government wants to have more young people engaged in and successfully completing tertiary education. Completing a vocational or professional qualification early in adult life has a higher return for both the individual and society. Those who enrol in tertiary education directly from schools are more likely to complete a qualification than students who enter from the work force, largely because school leavers are 'more likely to study full time and have fewer other commitments', according to the Tertiary Education Strategy 2010-2015 (Ministry of Education, 2010, p. 12). While this is a very important strategic recognition, it has some conflicting goals, and thus needs some kind of balancing act. In order to achieve the desired final outcome, that is, a return on time and money invested for 
both the individual and society, employability at the end of the process is a requirement. From this it becomes relevant to examine what qualities potential employers expect from students - that is, academic qualification with best grades at younger age or graduates with average grades because of paid semester work in combination with academic study. Further when the funding model is linked to completion and retention, tertiary educational institutions (TEIs) drive to enrol more full-time students (mostly school leavers), rather than focusing on the actual mechanics of work and study arrangements. Thus it is yet to be seen whether this strategy will lead to the ultimate outcome of employability or student completions, in relation to levels of funding for TEIs. Therefore the investigation of undergraduate students balancing paid semester work and study has significant implications in the light of the New Zealand Government's new Tertiary Education Strategy 2010-2015.

\section{Methodology}

\section{Instrument}

The self-report questionnaire of Manthei and Gilmore (2005) was used as the basis for the replication study. The undergraduate bachelor participants for the present study were enrolled at the Eastern Institute of Technology (EIT) in seven undergraduate degrees. Permission by Manthei and Gilmore was given for the use of their survey instrument. The main difference in execution of data collection was that the present study used an online survey rather than a paper-based one. Institutional subscription to SurveyMonkey

http://www.surveymonkey.com/) provided the structure within which the questions were prepared for online completion. In a few cases questions were slightly modified, such as replacing the word "university" with "institution". In contrast to the paper-based survey handout and receipt all on one day in the Manthei and Gilmore study, the present study being online remained available to students for about a month, and included a follow up email encouraging completion of the survey.

Eighty one students attempted the survey out of a total sample of approximately 600 , representing a response rate of $14 \%$. Students were advised that participation was optional. This was a similar number to eighty-three respondents in the Manthei and Gilmore study. A technical problem in setting up the online survey meant that switching between the "pages" of the survey blocked some students from completing the survey. Although this was rectified it lowered the overall response rate. Unrelated to the technical problem, the survey results showed students making their own decisions to discontinue or selectively answer questions at various points through the survey.

\section{Results and Discussion}

The part of the replication of the Manthei and Gilmore study that is reported here centres around the first two Tables presented in their article. The two tables presented below here set out the comparison with the earlier study by reporting the corresponding Manthei and Gilmore's results with the results from the present study together in the same table, for each of the tables in turn. Analysis and tabulation of data collected from SurveyMonkey on-line questionnaire was stored in an Excel spreadsheet, and then imported into SPSS version 18 (Statistical Package for the Social Sciences). Reporting of the statistical analysis is restricted here to comparison between the present results and the Manthei and Gilmore data. Qualitative responses to relevant questions are discussed separately.

\section{Aspects of Students' Workload}


Table 1 cross-tabulates responses for questions 7 and $12 \mathrm{c}$, time spent spread across the days of the week in terms of hours spent in class and in paid work. The key finding in Table 1 can also be seen in Figure 1, that students paid work in these two results has increased from 32.5 hours per week to 42.1 hours. This is a significant increase $(30 \%)$. The possible reasons for this increase may include the following: a continuing shift to the user pay model of tertiary education and resultant increase in student debt; the geographical location of EIT and the availability of student jobs in this region; and the realisation that work experience and work habits during undergraduate study is seen as positive feature in securing employment later on. During the intervening period between these two studies there has not been any significant change in degree programs in general or course structure in particular.

A further observation that provides context for the reported increase of approximately ten hours in student semester time paid employment is the relatively unchanged amount of in-class work undertaken. By adding a total column to the Manthei and Gilmore Table 1, comparison with the present overall hours can be made. This shows a slight increase from 15.6 class contact hours per week to 16.5 hours. This suggests a broad formal uniformity across different kinds of tertiary institutions in New Zealand in their class contact hours for undergraduate degree students. See, however, the further comments in the first paragraph of the next subsection which looks at the amalgamation of class and paid work hours.

Table 1: Average Daily Hours Spent in Class and Paid Work

\begin{tabular}{|c|c|c|c|c|c|c|c|c|}
\hline & Monday & Tuesday & Wednesday & Thursday & Friday & Saturday & Sunday & Total \\
\hline \multicolumn{9}{|c|}{ M \& G study } \\
\hline In class & 2.5 & 4.0 & 3.9 & 2.6 & 2.5 & 0.1 & - & 15.6 \\
\hline \multirow[t]{2}{*}{ Paid work } & $\underline{4.0}$ & $\underline{3.6}$ & $\underline{4.2}$ & $\underline{4.0}$ & $\underline{4.6}$ & $\underline{6.3}$ & $\underline{5.8}$ & $\underline{32.5}$ \\
\hline & $\underline{6.5}$ & $\underline{7.6}$ & $\underline{8.1}$ & $\underline{6.6}$ & $\underline{7.1}$ & $\underline{6.4}$ & $\underline{5.8}$ & $\underline{48.1}$ \\
\hline \multicolumn{9}{|c|}{ Present Study } \\
\hline In class & 3.3 & 3.7 & 3.3 & 4.2 & 2.0 & - & - & 16.5 \\
\hline \multirow[t]{2}{*}{ Paid work } & $\underline{5.9}$ & $\underline{6.4}$ & $\underline{5.7}$ & $\underline{6.0}$ & $\underline{7.2}$ & $\underline{5.6}$ & $\underline{5.3}$ & $\underline{42.1}$ \\
\hline & $\underline{9.2}$ & $\underline{10.1}$ & 9.0 & $\underline{10.2}$ & 9.2 & $\underline{5.6}$ & $\underline{5.3}$ & $\underline{58.6}$ \\
\hline
\end{tabular}

Figure 1: Total Hours Spent in Class and Paid Work 


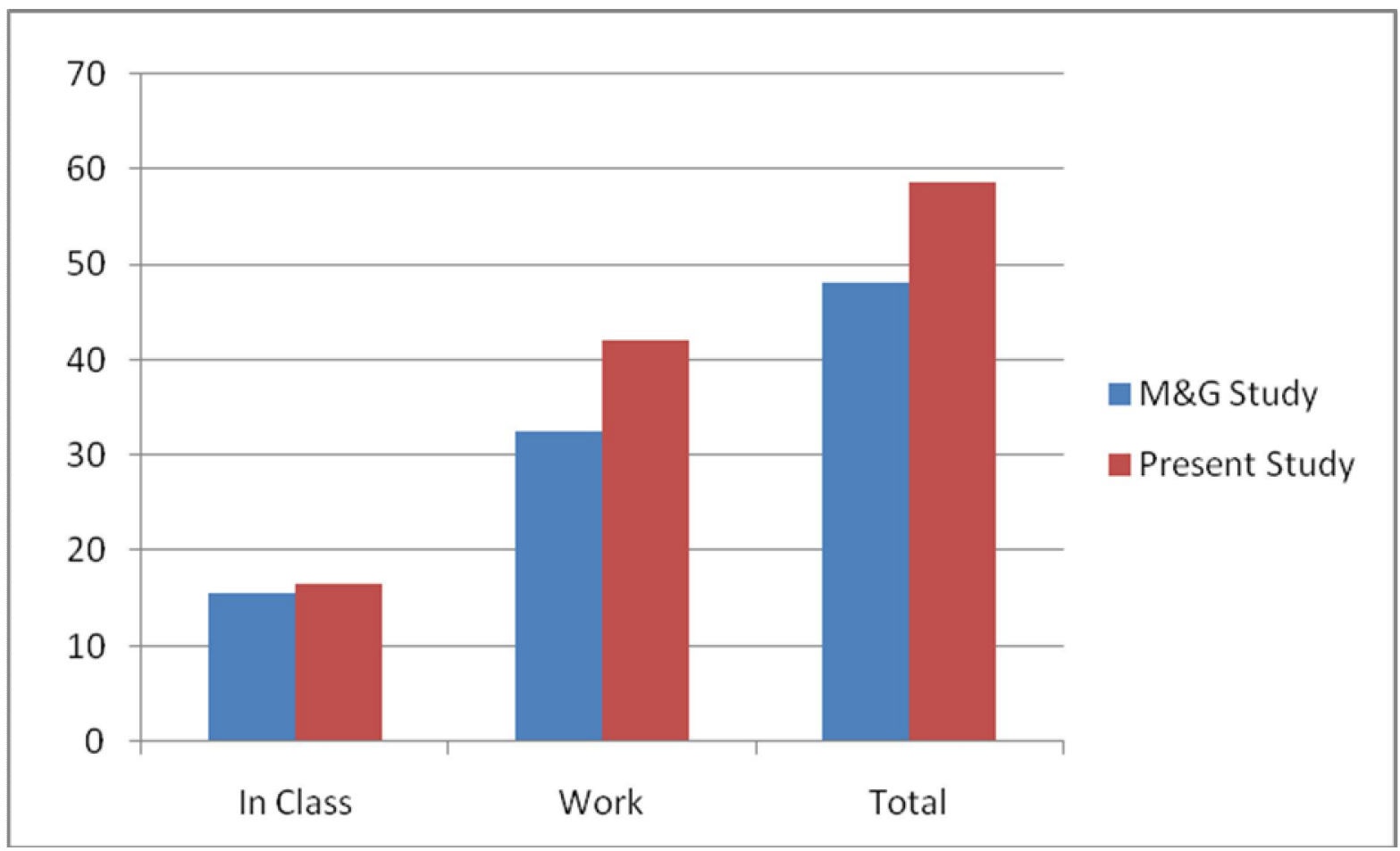

Manthei and Gilmore noted that in the weekly spread of class hours by day of the week, the 'longest work days being days with fewer in-class commitments, e.g. Thursdays through Mondays'. The daily weekday average hours in class plus paid work in the present study was between 910 hours, dropping by almost half in the weekends - no classes being the major, but not sole factor. This contrasted with about 6.5-8 hours of class and paid work combined in the Manthei and Gilmore study, with very little dip in time commitment at weekends. Only Friday in the present study showed the inverse relationship between paid work and class contact hours suggested by Manthei and Gilmore (Table 1).

\section{Paid Employment during Semester}

In the present study, the sum of weekly averages for time spent in class (13.2 hours) and hours spent studying outside of class (15.4 hours) was 28.6 hours per week. This figure equates to $72 \%$ of a typical 40 hour work week. This contrasts with the Manthei and Gilmore study result where the sum of weekly averages for time spent in class (13.3 hours) and hours spent studying outside of class (12.6 hours) was 25.9 , which was $65 \%$ of a typical 40 hour work week. This is an interesting result in terms of trying to understand an overall impact on student energy, focus and time. In addition, students work much longer hours per week (27.3 hours) compared to both 'perceived ideal' (19.8) and the previous study (13.8). The huge jump in time spent in paid work, must have significant impact on educational performance, retention and completion rates. The reasons for working longer hours are likely to be wide and varied. However, possible factors for this may include the present relatively high cost of tertiary education and student loans. While students perceive ideal work hours per week as 19.8 in contrast to their actual reported work amount at 27.3 hours, there must be some compelling reasons. In the area of 'sports and recreation' it can be seen a significant negative variance between the ideal (15.4 hours) and actual (7.6 hours).

Adding a total column to Table 1 has surfaced a discrepancy between the weekly hours in class reported in response to a 
direct question and the sum of the hours students reported day by day. Manthei and Gilmore did not explain this difference in their article. Here, we note that it is paralleled in the present study, and further that the difference is parallel in magnitude in the two studies. The difference may be an artefact of the way the two questions collected the information, and one argument would be that the more finegrained information (daily hours) provides a more exact reportage of time spent.

Table 2: The Number of Hours Students Spent and would like to spend on Different Activities

\begin{tabular}{|c|c|c|c|c|c|c|}
\hline \multirow{2}{*}{ Activity } & \multicolumn{2}{|c|}{$\begin{array}{l}\text { Hours actually } \\
\text { spent }\end{array}$} & \multicolumn{2}{|c|}{$\begin{array}{c}\text { Perceived Ideal } \\
\text { Hours } \\
\end{array}$} & \multicolumn{2}{|c|}{$\begin{array}{c}\text { Ideal Balance of } \\
\text { Hours }\end{array}$} \\
\hline & Mean & SD & Mean & $\mathrm{SD}$ & Mean & $\mathrm{SD}$ \\
\hline \multicolumn{7}{|l|}{ M \& G study } \\
\hline University classes & 13.3 & 6.0 & - & - & - & - \\
\hline Study outside classes & 12.6 & 8.1 & 15.5 & 10.1 & 19.1 & 10.5 \\
\hline Work & 13.8 & 10.8 & 12.8 & 7.7 & 11.0 & 6.5 \\
\hline Sport/recreation & 7.3 & 5.7 & 9.3 & 5.0 & 10.2 & 5.6 \\
\hline Total hours per week & 47.0 & & 50.9 & & & \\
\hline \multicolumn{7}{|l|}{ Present Study } \\
\hline Polytechnic classes & 13.2 & 6.9 & - & - & - & - \\
\hline Study outside classes & 15.4 & 10.9 & 18.4 & 10.9 & 24.4 & 12.9 \\
\hline Work & 27.3 & 16.7 & 19.8 & 13.3 & 14.1 & 11.1 \\
\hline Sport/recreation & 7.6 & 6.4 & 15.4 & 11.0 & 13.9 & 8.6 \\
\hline Total hours per week & 63.5 & & 63.6 & & & \\
\hline
\end{tabular}

It can be seen that students reported a significant increase in all time uses in responding to the questions about 'Ideal Balance of Hours', in comparison to the Manthei and Gilmore study. Namely, 'study outside class' increased from 19.1 to 24.4 and 'work' from 11.0 to 14.1 and 'sports/recreation' from 10.2 to 13.9 hours. This is again an interesting result. The 'Balance' that was acceptable in the 2002, Manthei and Gilmore study, is still valid in relative terms (ratios) but not absolute terms. The possible reasons for increase in hours in absolute terms may include; more take home assignments, group work, presentations becoming more prevalent, and also students taking responsibility for their learning using electronic media or internet options compared to previously. Increased hours of paid work in the preferred balance may be a result of high student loans and present user pay model of funding. An interesting observation of this Table 2 is that 'Balance' between the three areas of time expenditure remains broadly the same. This is the case even though the total hours identified by students as an ideal balance has increased by over ten hours (12.1).

In both studies students recognised they might ideally be doing a little more study outside their classes than they were currently doing (2.9 hours extra, and 3.0 hours respectively). When the questions is asked of an overall accumulation of hours spent on classes, outside study, paid work and sorts/recreation, Manthei and Gilmore note that students in their study reported doing a total of 47 hours but felt and additional four hours per week would be ideal. In contrast, students in the present study reported an ideal amount of time on a considerable higher current amount 
(63.5 hours) - almost identical to what they were already doing (63.6 hours). Perhaps understandably they felt they could not stretch this further. Again, a number of factors may be at work here.

Further comparison with Manthei and Gilmore can be made in terms of students' responses to what they considered the ideal balance of hours spent in various activities. The earlier study found an ideal hours spent balance for the three categories of study, work and leisure of 19.1, 11.0 and 10.2 respectively

In Table 2 students reported their perceived ideal amount of hours for paid semester work per week, 12.8 hours for the earlier study and 19.4 for the represent study. This can be read in light of the actual hours reported. For the Manthei and Gilmore study the 13.8 hours currently worked is about half the average paid work hours for the present study group. The ideal differential, however, is that the present group of students report wishing to cut their paid work load by about $27 \%$, whereas the earlier group with a much lighter paid work load reported an average preference to reduce paid work by $7 \%$.

Manthei and Gilmore use the idea of the 40 hours week to analyse the accumulated time commitment of students, beyond the in-class and out of class study. Table 2 allows a comparison of this additive process. Reading down column one it does this firstly by reporting paid work, and then showing the time spent in sport and recreation activities.

When these figures were combined with the respective hours of study outside class, 15.4 hours in this study compared to an 12.6 hours in the earlier study, the totals were 28.6 hours for the present study and 25.9 hours for the earlier study (Table 2). Manthei and Gilmore noted their figure was 65 percent of 'a typical 40 hour week'; in the present study the extra 2.7 hours of students' time could be similarly read as closer to three quarters (72 percent) of this notional working week.

\section{Conclusions}

This paper has explored findings from a current study looking at tertiary students' paid work during semester time in relation to a previous study by Gilmore and Manthei. The findings reported here are again only indicative from a very small informational base. The results and discussion do, however, have the additional value of comparison to the earlier Manthei and Gilmore results. The major difference between the studies was the additional ten hours, approximately quarter of a notional forty hour week, additional paid work the present study participants undertook during semester weeks compared with the Manthei and Gilmore study participants. Regardless of the causes, if this finding is borne out in other research it has important implications for students individually and also for the government's current mediumterm strategic plan. Areas of educational performance that may be impacted include retention, academic quality and completion of qualifications.

A number of differences in the student population may be contributing factors to the much higher paid semester work loads reported in the present study. These may include a different tertiary institution, the different segment of the tertiary sector, the different degree programs involved. The geographic region, and the time difference of eight years (2002-2010) in changing attitudes and expectations of students, are factors that may also play a part. Finally, something that was not measured directly but which may be involved in the other factors just listed, is the socio-economic status of students may have a bearing on their educational capital and abilities as well as their family and economic resources to fund their tertiary study. 
Further investigation of the mixture of these factors involved in current student workloads is an important research goal. Further analysis of the present results is one art of this. By accurately identifying the drivers of student paid semester work, and forming an assessment of beneficial and deleterious educational consequences, tertiary education policy settings can more accurately target semester paid work effects for students in relation to the desired medium term strategic intentions for the sector.

\section{References}

Bernhard, H. C. (nd). A comparison of burnout between undergraduate music and nonmusic majors. Available at http://wwwusr.Rider.Edu/ vrme/v9n1/vision/bernard \%20final.Pdf (January 12, 2010).

Hunt, A., Lincoln, I. and Walker, A. (2004). Term-time employment and academic attainment: Evidence from a large-scale survey of undergraduates at Northumbria University. Journal of Further and Higher Education, 28, 1, 3-18.

Manthei, R. and Gilmore, A. (2005). The effect of paid employment on university students' lives. Education and Training, 47, 3, 202-215.
McInnis, C. and Hartley, R. (2002). Managing study and work: The impact of full-time study and paid work on the undergraduate experience in Australian universities, executive summary. Department of Education, Science and Training, Evaluations and Investigations Programme (EIP), Canberra, ACT. Retrieved January 12, 2010 from http://www.Dest.Gov.Au/archive/highered /eippubs/eip02_6/executive_summary.Ht $\mathrm{m}$

Lingard, H. C. (2007). Conflict between paid work and study: Does it impact upon students' burnout and satisfaction with university life? Journal for Education in the Built Environment, 2, 1, 90-109.

Plimmer, G. and Schmidt, A. (2007). Possible selves and career transition: It's who you want to be, not what you want to do. New Directions for Adult and Continuing Education, 114, 61-74.

RMIT University. (2004). Background Reading, Student Life: Current and Emerging Trends. International Research Consultancy Unit (IRCU), RMIT Planning Group, RMIT University, Melbourne. Available at http://www2.rmit.edu.au/departments/plan ning/ircu/studentlife/docs/IRCUESStudentLifeVol03.pdf (January 12, 2010).

Ministry of Tertiary Education. (2010). Tertiary Education Strategy 1010-2015. National Office: Wellington, New Zealand. 